\title{
Blink reflexes in posterior fossa lesions
}

\author{
B. ROS I, R. B U O N A G U I I, A. MURA T OR IO, A N D G T US I N I \\ From the 2nd Clinic of Neurology and Institute of Neurosurgery, University of Pisa, Pisa, Italy
}

SUMMARY Blink reflexes obtained by electrical stimulation of the supraorbital nerve and electromyographic recording of the orbicularis oculi muscle proved useful as a preliminary method in diagnosis of lesions of the brainstem and the fifth and seventh cranial nerves, and in differentiating intrinsic lesions of the brainstem from extrinsic ones. It was noted that R1 and $\mathrm{R} 2$ reflexes were different in the two types of lesions.

Electric stimulation of the supraorbital nerve and electromyographical registration of the orbital muscle of the eyelids give two distinct responses (Kugelberg, 1952; Rushworth, 1962), a first early response (R1), ipsilateral to the stimulated side, relatively constant in duration and shape, synchronous, and which only very slowly dies out with repetitive stimulation; and a second late response (R2), which corresponds to clinically observable blinking. The latter response is variable in duration and morphology of the action potential. It is asynchronous and rapidly habituates, disappearing bilaterally. $\mathrm{R} 1$ has a latency of $10.6 \pm 2.5 \mathrm{~ms}$; direct R2 latency is $31 \pm 10 \mathrm{~ms}$, that of the consensual R2 is $32 \pm 11 \mathrm{~ms}$ (Kimura, 1973). Because of its anatomical and physiological characteristics, this reflex has been the object of investigations in various pathological conditions of the posterior cranial fossa, of the brainstem and, particularly, in lesions of some cranial nerves.

There were pathological findings in 11 cases reported by Eisen and Danon (1974) who were affected by neurinoma of the acoustic nerve. Positive results for this test were reported by Lyon and Van Allen (1972) even in patients with few symptoms. Clay and Ramseyer (1977) believe that in the functional study of the brainstem the registration of blink reflexes gives information which other tests do not provide. According to Kimura (1973), a difference in R1 latency between the two sides greater than $1.2 \mathrm{~ms}$ is abnormal. Two types of comparison are possible in the case of R2: (a) unilateral stimulation should not be associated with differences in latency between

Address for reprint requests: Dr Bruno Rossi, $2^{\circ}$ Clinica Neurologica, Spedali Riuniti S. Chiara, Via Roma 5, 56100 Pisa, Italy.

Accepted 20 November 1978 direct and consensual $\mathrm{R} 2$ exceeding $5 \mathrm{~ms}$; (b) the difference between the direct $\mathrm{R} 2$ latencies of the two sides must not be greater than $8 \mathrm{~ms}$.

Alteration of early reflex $\mathrm{R} 1$ indicates a delay in stimulus conduction due either to an intrinsic pontine lesion, or to an extrinsic compression of the pons, or to direct involvement of the facial or trigeminal nerves. Analysis of R2 is useful in distinguishing between lesions to the afferent or efferent pathways. In fact, bilateral R2 delays (for example, direct on the right and consensual on the left) reveal the presence of a lesion somewhere along the afferent path (right trigeminal nerve, spinal tract, trigeminal nucleus in the medulla and in the pons).

On the other hand, a unilateral R2 delay-for example, direct on the right (stimulus on the right) and consensual on the right (stimulus on the left) -is present when there is a lesion somewhere along the right efferent pathway (right facial nerve or right side of the pons).

In this paper we analyse the importance of blink reflexes in lesions of the posterior cranial fossa, particularly with regard to data useful in differentiating between intrinsic and extrinsic lesions of the brainstem.

Our investigation concerned 21 patients affected by the following diseases: (a) cerebello-pontine angle lesions (eight cases of acoustic neurinoma, three cases of petrous ridge meningioma); (b) brainstem lesions (two intrinsic neoplasms, one haemorrhage from arteriovenous malformation (AVM), two basilar artery occlusions); (c) diencephalic, posterior region of the third ventricle and quadrigeminal body lesions (one vascularised neoplasm of the pineal region, one diencephalic neoplasm reaching as far as the quadrigeminal bodies); (d) cerebellar lesions (one medullo- 
blastoma, two hemispheric metastases, one cerebellar convexity meningioma).

\section{Method}

Blink reflexes were recorded from the orbicular muscle of the lower eyelid, using surface electrodes. The electric stimuli consisted of discrete rectangular pulses of 0.2 ms duration, with supramaximal intensity, applied at the level of emergence of the first trigeminal branch from the supraorbital foramen, by means of superficial electrodes. The responses thus obtained were recorded on photographic paper for subsequent measurements (latency, duration, and amplitude). Electromyography of the orbicularis oculi muscle was also performed. Medelec instruments were used. Data on the values of the R1 and R2 reflex responses and on EMG examinations are reported in Table 1.

\section{Results}

When cerebellopontine angle lesions were present the following results were obtained. On the affected side $R 1$ was absent in three cases $(1,4,10)$. The latency of $\mathbf{R} 1$ was pathologically increased in four cases $(2,6,8,9)$. The latency was within normal limits, but significantly increased as compared to the contralateral side in three cases $(3,5,7) . \mathrm{R} 1$ latency was also increased on the side opposite to the lesion in two cases $(1,8)$. The difference in $\mathrm{R} 1$ latency between the two sides ranged from 2 to $11 \mathrm{~ms}$. Direct R2 was absent in one case (10), and had an increased latency in two (cases 2,8 ); consensual R2 latency was increased in case 10 . The

Table 1 Summary of values of $R 1$ and $R 2$ reflex responses and EMG results

\begin{tabular}{|c|c|c|c|c|c|c|c|c|}
\hline \multirow[t]{2}{*}{ Case } & \multirow[t]{2}{*}{ Initials } & \multirow{2}{*}{$\begin{array}{c}\text { Age } \\
(y r)\end{array}$} & \multirow[t]{2}{*}{ Lesion } & \multirow[t]{2}{*}{ Side } & \multicolumn{3}{|c|}{ Blink reflexes, latencies } & \multirow[t]{2}{*}{$E M G$} \\
\hline & & & & & $\begin{array}{l}R I \\
m s\end{array}$ & $\begin{array}{l}\text { R2 direct } \\
\mathrm{ms}\end{array}$ & $\begin{array}{l}R 2 \text { consensual } \\
\mathrm{ms}\end{array}$ & \\
\hline 1 & DA & 48 & Right acoustic neurinoma & $\begin{array}{l}\mathbf{R} \\
\mathbf{L}\end{array}$ & $\begin{array}{l}\text { absent } \\
15\end{array}$ & $\begin{array}{l}39 \\
34\end{array}$ & $\begin{array}{l}33 \\
36\end{array}$ & + \\
\hline \multirow[t]{2}{*}{2} & NO & 56 & Right acoustic neurinoma & $\mathbf{R}$ & 14,5 & 42 & 37 & - \\
\hline & & & & $\mathbf{L}$ & 11 & 37 & 41 & - \\
\hline \multirow[t]{2}{*}{3} & BA & 29 & Left acoustic neurinoma & $\mathbf{R}$ & 10 & 28 & 30 & - \\
\hline & & & & $\mathbf{L}$ & 12,5 & 30 & 28 & + \\
\hline \multirow[t]{2}{*}{4} & CG & 56 & Left acoustic neurinoma & $\mathbf{R}$ & 13 & 38 & 43 & - \\
\hline & & & & $\mathbf{L}$ & absent & 38 & 40 & + \\
\hline \multirow[t]{2}{*}{5} & TA & 54 & Left acoustic neurinoma & $\mathbf{R}$ & 10,4 & 26 & 27 & - \\
\hline & & & & $\mathbf{L}$ & 12,4 & 30 & 29 & + \\
\hline \multirow[t]{2}{*}{6} & BP & 19 & Bilateral acoustic neurinoma & $\mathbf{R}$ & 13,6 & 31 & 30 & + \\
\hline & & & & $\mathbf{L}$ & 16 & 35 & 31 & + \\
\hline \multirow[t]{2}{*}{7} & DM & 71 & Right acoustic neurinoma & $\mathbf{R}$ & 12 & 30 & 30 & - \\
\hline & & & & $\mathbf{L}$ & 10 & 30 & 30 & - \\
\hline \multirow[t]{2}{*}{8} & UN & 56 & Left petrous ridge meningioma & $\mathbf{R}$ & 14 & 38 & 39 & + \\
\hline & & & & L & 25 & 45 & 40 & + \\
\hline \multirow[t]{2}{*}{9} & MF & 60 & Right petrous ridge meningioma & $\mathbf{R}$ & 14 & 35 & 35 & - \\
\hline & & & & $\mathbf{L}$ & 12,2 & 35 & 35 & - \\
\hline \multirow[t]{2}{*}{10} & GD & 60 & Right petrous ridge meningioma & $\mathbf{R}$ & absent & absent & 45 & \\
\hline & & & & $\mathbf{L}$ & 11,5 & 35 & 35 & \\
\hline \multirow[t]{2}{*}{11} & MR & 8 & Pontine tumour & $\overline{\mathbf{R}}$ & absent & absent & 38 & + \\
\hline & & & & $\mathbf{L}$ & 11 & 35 & 42 & - \\
\hline \multirow[t]{2}{*}{12} & MB & 4 & Mesencephalic pontine tumour & $\mathbf{R}$ & 14,4 & absent & absent & + \\
\hline & & & & $\mathbf{L}$ & 13,7 & absent & absent & + \\
\hline \multirow[t]{2}{*}{13} & GS & 12 & AVM with pontine haemorrhage & $\mathbf{R}$ & 10,5 & 37 & absent & - \\
\hline & & & & $\mathbf{L}$ & absent & absent & & + \\
\hline 14 & MA & 52 & Basilar artery occlusion & $\begin{array}{l}\mathbf{R} \\
\mathbf{L}\end{array}$ & $\begin{array}{l}\text { absent } \\
\text { absent }\end{array}$ & $\begin{array}{l}\text { absent } \\
\text { absent }\end{array}$ & $\begin{array}{l}\text { absent } \\
\text { absent }\end{array}$ & \\
\hline \multirow[t]{2}{*}{15} & DGA & 28 & Basilar artery occlusion & $\mathbf{R}$ & 10,2 & absent & absent & \\
\hline & & & & $\mathrm{L}$ & 10,4 & absent & absent & \\
\hline \multirow[t]{2}{*}{16} & GP & 9 & Medulloblastoma & $\overline{\mathbf{R}}$ & 9,4 & 30 & 30 & - \\
\hline & & & & $\mathbf{L}$ & 10,4 & 30 & 30 & - \\
\hline \multirow[t]{2}{*}{17} & NM & 65 & Left cerebellar hemisphere metastasis & $\overrightarrow{\mathbf{R}}$ & 12,3 & 32 & 42 & - \\
\hline & & & & $\mathrm{L}$ & 12,7 & 36 & 36 & - \\
\hline 18 & SL & 50 & Right cerebellar hemisphere metastasis & $\mathbf{R}$ & 10 & 32 & 32 & - \\
\hline & & & & $\mathbf{L}$ & 10 & 30 & 30 & - \\
\hline 19 & PD & 57 & Left convexity cerebellar meningioma & $\mathbf{R}$ & 9,5 & 34 & 37 & + \\
\hline & & & & $\mathbf{L}$ & 15,5 & 43 & 47 & + \\
\hline 20 & $\mathbf{C P}$ & 14 & Pineal tumour & $\overline{\mathbf{R}}$ & 11 & 32 & 35 & - \\
\hline & & & & $\mathbf{L}$ & 11 & 35 & 35 & - \\
\hline 21 & BC & 13 & Right diencephalic upper mesencephalic glioma & $\mathbf{R}$ & 12,7 & 40 & 42 & - \\
\hline & & & & $\mathbf{L}$ & 13 & 38 & 35 & - \\
\hline
\end{tabular}


EMG was pathological in seven cases.

In patients with intrinsic lesions of the brainstem we observed that $R 1$ was absent on one side in two cases (11 and 13) and bilaterally in one (case 14). Latency of $R 1$ was bilaterally increased in one case (12). R1 latency was within normal limits in a single patient (15); R2 was absent on one side in two (cases 11,13) and bilaterally in three patients $(12,14,15)$. Electromyography, when performed, always proved to be abnormal.

In the two patients with expanding lesions of diencephalon, posterior region of third ventricle and quadrigeminal bodies, the blink reflexes were normal without significant differences between R1 and $\mathrm{R} 2$ latencies.

In patients with cerebellar lesions the following results were obtained. The patient (19), with an enormous meningioma of the cerebellar convexity and compression of the brainstem at the level of the pons, had an increased R1 latency on the affected side, and increased latencies of direct and consensual $\mathbf{R} 2$ responses on the same side. In the other three patients with lesions of the vermis or at the paramedian level, reflexes were normal or not significantly different between the two sides. Table 2 gives a comparison of the data obtained from the radiological examination of the petrous bone, the CAT scan, the audiological and vestibular tests and so on, with blink reflexes.

\section{Discussion}

The data reported show that the $\mathrm{R} 1$ response on the affected side was absent or had increased latency, either absolutely or in comparison with the healthy side, in all our patients with cerebello-

Table 2 Comparison of data from radiological, CAT scan, and other investigations with blink reflex responses

\begin{tabular}{|c|c|c|c|c|c|c|c|c|c|}
\hline Case & Initials & $\begin{array}{l}\text { Age } \\
(y r)\end{array}$ & Lesion & $\begin{array}{l}\text { Plain skull } \\
\text { radiograph } \\
\text { and } \\
\text { tomography }\end{array}$ & $\begin{array}{l}\text { Audiology and } \\
\text { vestibular tests }\end{array}$ & $\begin{array}{l}\text { Pneumocistern- } \\
\text { ography }\end{array}$ & $\begin{array}{l}C A T \\
\text { scan }\end{array}$ & $\begin{array}{l}\text { Vertebral } \\
\text { arterio- } \\
\text { graphy and } \\
\text { others }\end{array}$ & $\begin{array}{l}\text { Blink } \\
\text { reflexes }\end{array}$ \\
\hline 1 & DA & 48 & Right acoustic neurinoma & $+t$ & ++ & & + & & ++ \\
\hline 2 & NO & 56 & Right acoustic neurinoma & ++ & ++ & ++ & & & + \\
\hline 3 & BA & 29 & Left acoustic neurinoma & + & + & & + & + & + \\
\hline 4 & CG & 56 & Left acoustic neurinoma & + & + & + & & $+t$ & ++ \\
\hline 5 & TA & 54 & Left acoustic neurinoma & + & + & & + & & + \\
\hline 6 & BP & 19 & Bilateral acoustic neurinoma & + & + & & + & & + \\
\hline 7 & DM & 71 & Right acoustic neurinoma & - & + & & + & & + \\
\hline 8 & UN & 56 & Left petrous ridge meningioma & ++ & + & & & + & ++ \\
\hline 9 & MF & 60 & Right petrous ridge meningioma & + & + & + & $+\cdot$ & $\begin{array}{l}\text { Right } \\
\text { carotid } \\
\text { arterio- } \\
\text { graphy + }\end{array}$ & + \\
\hline 10 & GD & 60 & Right petrous ridge meningioma & + & ++ & + & + & - & ++ \\
\hline 11 & MR & 8 & Pontine tumour & & & ++ & & & ++ \\
\hline 12 & MB & 4 & Mesencephalic pontine tumour & & & & + & & + \\
\hline 13 & GS & 12 & AVM with pontine haemorrhage & & & & & ++ & ++ \\
\hline 14 & MA & 52 & Basilar artery occlusion & & + & & & ++ & ++ \\
\hline 15 & DGA & 28 & Basilar artery occlusion & & + & & & ++ & ++ \\
\hline 16 & GP & 9 & Medulloblastoma & & + & & + & & - \\
\hline 17 & NM & 65 & Left cerebellar hemisphere metastasis & & & & & $\begin{array}{l}\text { Iocarmate } \\
\text { ventricu- } \\
\text { lography }+ \\
\text { Brain scan }+\end{array}$ & - \\
\hline 18 & SL & 50 & Right cerebellar hemisphere metastasis & & & & & $\begin{array}{l}\text { Right } \\
\text { carotid } \\
\text { arterio- } \\
\text { graphy + }\end{array}$ & - \\
\hline 19 & PD & 57 & Left convexity cerebellar meningioma & & + & & & $\begin{array}{l}\text { locarmate } \\
\text { ventricu- } \\
\text { lography }+\end{array}$ & + \\
\hline 20 & CP & 14 & Pineal tumour & & & & & $\begin{array}{l}\text { Right } \\
\text { carotid } \\
\text { arterio- } \\
\text { graphy + }\end{array}$ & - \\
\hline 21 & BC & 13 & $\begin{array}{l}\text { Right diencephalic upper } \\
\text { mesencephalic glioma }\end{array}$ & & & & & $\begin{array}{l}\text { Brain } \\
\text { scan + } \\
\text { Right } \\
\text { carotid } \\
\text { arterio- } \\
\text { graphy + }\end{array}$ & - \\
\hline
\end{tabular}

$-=$ normal $;++,+=$ more or less pathological. 
pontine angle lesions. Sometimes the $\mathrm{R} 1$ on the side contralateral to the lesion also had increased latency. This could be the result of involvement of the opposite side caused by rotation of the brainstem. This EMG finding may precede the appearance of clinical signs of contralateral brainstem damage. The volume of the expanding lesion seems to be directly related to the extent of $R 1$ delay; in fact latencies were found to be higher (or the early reflex was absent) in those cases in which surgery revealed the tumours of larger size with enlargement of the internal acoustic meatus or destruction of the apex of the petrous bone and with compression of the brainstem.

Bender et al. (1969) were among the first to report the delay observable in the early response of the blink reflex of four patients with acoustic neurinoma, later confirmed by surgery. Lyon and Van Allen (1972), reporting a further five cases of neurinoma of the eighth cranial nerve, confirmed Bender's data. In the electrodiagnostic study of 11 patients with cerebellopontine angle tumours reported by Eisen and Danon (1974), all had an increased R1 latency of the affected side (in five it was absent) and in eight cases, after stimulation of the affected side, an increased consensual R2 latency. The latter result showed that the fifth cranial nerve was also involved.

The conduction velocities, sometimes clearly abnormal, found in our investigation, led us to believe that performance of this test at an early stage of the disease, could already reveal the presence of an alteration.

Blink responses behave in quite a different way when intrinsic lesions of the brainstem are involved. When the response may still be evoked, as a rule, the latency is within normal limits (except our case 12 where latency was only slightly increased). In particular, in cases 11 and $13, \mathrm{R} 1$ and R2 were absent on one side, while the response obtained by stimulating the other side had normal latency. Another peculiarity was the absence of $\mathrm{R} 2$ and maintenance of $\mathrm{R} 1$. This may be explained by the different mechanism of lesions of the brainstem and of cranial nerves in the two types of pathology. In case 14 no response could be obtained, either early or late. This patient, with thrombosis of the basilar artery, had a "locked-in syndrome," and could only communicate by means of vertical movements of the eyes. As in other cases in which $R 1$ and $R 2$ were absent on one side, registration of the direct motor response, from stimulating the facial nerve, provided additional information on conditions of the brainstem. In fact, if it is still possible to evoke such a direct motor response, it may be deduced that the nucleus of the seventh cranial nerve is as yet relatively uninvolved, in spite of the pontine lesion responsible for disappearance of $\mathrm{R} 1$. Our results are in agreement with those of Clay and Ramseyer (1977), who found R1 to be absent or with normal latency and direct or consensual R2 almost always absent in 12 children with brainstem tumours (intrinsic glioma).

When there are lesions which only partially involve the higher part of the brainstem (as in our two patients who had expansive processes in one case at the level of the diencephalon, in the other in the pineal region, both with involvement of the quadrigeminal bodies) but not reaching the reticular formation, early and late reflex responses are within normal limits.

Blink reflexes may be valuable in patients with cerebellar lesions to assess whether the brainstem is compressed or not. Kimura and Lyon (1973 and Raman et al. (1976) reported that the responses obtained in posteriorly localised expanding lesions of the cerebellum were within normal limits. We also found in the patients with tumours in the posterior fossa (cases 16, 17, 18)-surgically demonstrated to be respectively a medulloblastoma of the vermis and two paramedian metastasesthat responses did not have increased latencies, nor were there significant differences between sides. Case 19, affected by an enormous men ingioma of the left cerebellar convexity, with brainstem compression, had a latency of $R 1$ on the affected side of $15.5 \mathrm{~ms}$, while direct and consensual R2, after stimulation on the left, had a latency of 43 and $47 \mathrm{~ms}$, indicating involvement of the left fifth and seventh cranial nerves.

Our results, in agreement with other reports, show the usefulness of blink reflexes, studied with an electromyographic technique, in the diagnosis of suspected lesions of the posterior cranial fossa. Its anatomical and physiological characteristics make it a valid test in confirming suspected lesions, even in their early stages, especially when localised at the cerebellopontine angle, and in assessing damage to the brainstem. Moreover, investigations such as cerebral angiography, pneumocisternoencephalography, and computerised axial tomography, though essential in identifying structural lesions, do not give information on the functional state of the brainstem, information which can be obtained by studying the blink reflexes correlated with the clinical study of the patient.

We would like to thank Dr Nadia Simonini for her assistance in the preparation of the manuscript. This work was supported in part by the CNR. 


\section{References}

Bender, L. F., Maynard, F. M., and Hastings, S. V. (1969). The blink reflex as a diagnostic procedure. Archives of Physiological Medicine, 50, 27-31.

Clay, S. A., and Ramseyer, C. (1977). The orbicularis oculi reflex: pathologic studies in childhood. Neurology (Minneapolis), 27, 892-895.

Eisen, A., and Danon, J. (1974). The orbicularis oculi reflex in acoustic neuromas: a clinical and electrodiagnostic evaluation. Neurology (Minneapolis), 24, 306-311.

Kimura, J. (1973). The blink reflex as a test for brainstem and higher nervous system function. In New Developments in Electromyography and Clinical Neurophysiology, vol. 3, pp. 682-691. Edited by J. E. Desmedt. Karger: Basel.
Kimura, J., and Lyon, L. (1973). Alteration of orbicularis oculi reflex by posterior fossa tumors. Journal of Neurosurgery, 5, 10-16.

Kugelberg, E. (1952). Facial reflexes. Brain, 92, 385396.

Lyon, L., and Van Allen, M. W. (1972). Alteration of orbicularis oculi reflex by acoustic neuroma. Archives of Otolaryngology, 95, 100-103.

Raman, P. T., Reddy, P. K., and Roo, S. V. (1976). Orbicularis oculi reflex and facial muscle electromyography: pre- and postoperative evaluation of posterior space occupying lesions. Journal of Neurosurgery, 44, 550-555.

Rushworth, G. (1962). Observations on blink reflex. Journal of Neurology, Neurosurgery, and Psychiatry, 25, 93-108. 